\title{
Sodium butyrate and tributyrin induce in vivo growth inhibition and apoptosis in human prostate cancer
}

\author{
R Kuefer', MD Hofer', ${ }^{1,3}$ Altug', C Zorn', F Genze', ${ }^{1,2}$ K Kunzi-Rapp',2, RE Hautmann' and JE Gschwend, \\ 'Department of Urology, University of Ulm, Prittwitz-Strasse 43, 89075 Ulm, Germany; ${ }^{2}$ Institute for Lasertechnology in Medicine, University of Ulm, \\ 89081 Ulm, Germany; ${ }^{3}$ Department of Pathology, Brigham \& Women's Hospital, Boston, MA 021 I5, USA
}

\begin{abstract}
Histone deacetylase inhibitors (HDACs) are known to exhibit antiproliferative effects on various carcinoma cells. In this study, the in vivo efficiency of two HDACs, sodium butyrate and tributyrin, on prostate cancer growth inhibition were investigated. To gain an insight into the possible underlying pathways, cell culture experiments were performed focusing on the expression of $\mathrm{p} 2 \mathrm{I}$, Rb and cmyc. For in vivo testing, prostate cancer cell lines (PC3 and TSU-Prl) were seeded on the chorioallantois membrane (CAM) and implanted in a xenograft model using nude mice. Standard Western blot analysis was performed for protein expression of p2 I, Rb and c-myc in HDAC-treated vs untreated prostate cancer cells. Both sodium butyrate and tributyrin had a considerable treatment effect on microtumours on the chicken egg at already very low concentrations of $0.1 \mathrm{mM}$. Tributyrin-treated tumours showed the strongest effect with 38\% apoptotic nuclei in the prostate cancer cell line PC3. In the mouse model, there was almost no difference between sodium butyrate and tributyrin. In untreated animals the tumours were almost double the size 4 weeks after implantation. Tumours of the treatment groups had a significantly lower percentage of Ki-67-positive-stained nuclei. As demonstrated by Western blot analysis, these effects seem to be independent of p53 status and a pathway via p $2 \mathrm{I}-\mathrm{Rb}-\mathrm{c}-\mathrm{myc}$ is possibly involved. In this study we have demonstrated a substantial in vivo treatment effect, which can be induced by the application of sodium butyrate or the orally applicable tributyrin in human prostate cancer. The given results may provide the rationale to apply these drugs in well-controlled clinical trials in patients being at high risk of recurrence after specific therapy or in patients with locally or distant advanced prostate cancer.
\end{abstract}

British Journal of Cancer (2004) 90,535-54I. doi:10.1038/sj.bjc.660I5I0 www.bjcancer.com

(c) 2004 Cancer Research UK

Keywords: sodium butyrate; tributyrin; HDAC; prostate cancer; in vivo; apoptosis

Prostate cancer has the highest incidence and is the second leading cause of cancer deaths among men in the United States (Jemal et al, 2002 ). With a response rate of about $80 \%$, androgen ablation induces apoptosis of normal prostate epithelial cells as well as regression of early-stage prostate cancer. However, progression to androgen independence occurs over time, so that this treatment option is not curative (Samson et al, 2002). Conventional chemotherapy has not sufficiently been proven to be effective either, especially in androgen-independent prostate cancer, and is limited by toxicity that is often aggravated by comorbidity of the elderly prostate cancer patients (Yagoda and Petrylak, 1993). Promising results of a single agent have so far been reported only by the usage of Docetaxel (Taxotere) (Picus and Schultz, 1999). There is a tremendous need to identify substances suitable for the prevention of progression and as a means for a better cancer control in advanced prostate cancer cases.

Agents that are active against prostate cancer alter cell growth and differentiation by modifying the expression of genes or gene products that regulate cell shape, function, adhesion and communication. Such compounds are for example butyrates, members of

\footnotetext{
*Correspondence: JE Gschwend;

E-mail: juergen.gschwend@medizin.uni-ulm.de

Received 05 August 2003; revised 29 October 2003; accepted 30

October 2003
}

the group of histone deacetylase inhibitors (HDACs) (Gleave et al, 1998). Butyrates are naturally occurring short-chain fatty acids leading to differentiation of numerous cell types (Chen and Breitman, 1994). The potential clinical utility of butyric acid is mainly limited by a short half-life in vivo as plasma concentrations decrease within minutes below the concentration needed for effects in vitro (Miller et al, 1987). To circumvent the problem of fast metabolism of butyrate monomers, analogues have been tested (Planchon et al, 1993). Tributyrin is a readily available trimer of butyric acid and is cleaved intracellular by lipases into three molecules of butyric acid. It has been shown that tributyrin can induce differentiation in human myeloid leukaemia cells, murine erythroleukaemia cells (Chen and Breitman, 1994), MCF-7 mammary carcinoma cells (Heerdt et al, 1999) and HT-29 colon cancer cells (Schroder et al, 1998). We have previously demonstrated that butyrates strongly induce in vitro growth inhibition and apoptosis in different human prostate cancer cell lines (Maier et al, 2000).

The objective of the present study was to determine whether in vivo prostate cancer tumour growth and progression are delayed under treatment with the butyrates sodium-butyrate and tributyrin. Testing was performed in vivo on the chorioallantois membrane (CAM) of fertilised chicken eggs (Kunzi-Rapp et al, 2001). For confirmation, a nude mouse model was explored with a study design of multiple dosing over 4 weeks. Immunohistochemistry for documentation of treatment-associated reduction of 
proliferation was performed. In addition, cell culture experiments were carried out to gain a further insight into the pathways possibly influenced by butyrates. Based on previous reports, the induction of $\mathrm{p} 21$, activation of the Rb protein and expression of $\mathrm{c}$ myc were evaluated under treatment conditions with the HDACs (Blagosklonny et al, 1997; Claassen and Hann, 2000; Rashid et al, 2001).

\section{MATERIALS AND METHODS}

\section{Cell culture and reagents}

The LNCaP, PC3 and Tsu-Pr1 cell lines were obtained from American Type Culture Collection (Rockwell, MD, USA). All cell lines were cultured and maintained in $5 \% \mathrm{CO}_{2}$ at $37^{\circ} \mathrm{C}$ in RPMI 1640 (Life Technologies, Eggenstein, Germany), supplemented with $10 \%$ heat-inactivated foetal calf serum, $2 \mathrm{~mm}$ L-glutamine, $100 \mathrm{U} \mathrm{ml}^{-1}$ penicillin $\mathrm{G}$ and $100 \mathrm{U} \mathrm{ml}^{-1}$ streptomycin (Life Technologies, Eggenstein, Germany). Sodium butyrate and tributyrin were obtained from Sigma-Aldrich Chemie GmbH (Deisenhofen, Germany). A stock solution of tributyrin was prepared using $100 \%$ ethanol. Sodium butyrate was dissolved in sterile water.

\section{Growth inhibition in cell culture}

For determining cell proliferation, the viable cell numbers were counted using the Cell Proliferation Kit II (Roche Diagnostics $\mathrm{GmbH}$, Mannheim, Germany) based on the XTT assay (Roehm et al, 1991). In brief, cells were grown in microtitre plates to $80 \%$ confluency. Cells were incubated with the given final concentration of the butyrates for $72 \mathrm{~h}$. After incubation, $50 \mu \mathrm{l}$ of XTT labelling mixture was added to each well. The microtitre plate was incubated for another $4 \mathrm{~h}$ before measuring absorbance at $492 \mathrm{~nm}$ (reference wavelength $690 \mathrm{~nm}$ ) of the samples using a microtitre plate reader (SLT spectra, Tecan GmbH, Crailsheim, Germany).

\section{Chorioallantois membrane}

Preparation and procedure of grafting Fertilised chicken eggs were incubated at $37.8{ }^{\circ} \mathrm{C}$ and $60 \%$ relative humidity. On day 4 of incubation, implantation was prepared. Standard microbiology testing was used to rule out subclinical infections. The procedure of preparing the CAM was carried out as described previously (Kunzi-Rapp et al, 2001). Briefly, a part of the CAM was exposed by peeling a round aperture of $2 \mathrm{~cm}$ diameter. The resulting window was covered with a self-adhesive stripe and incubation was continued. At day 7 of incubation, a silicone ring with a thickness of $0.5 \mathrm{~mm}$ and an inner diameter of $6 \mathrm{~mm}$ was placed onto the membrane. The cells were seeded into the ring at a concentration of $5 \times 10^{5}$ cells in $25 \mu \mathrm{l}$ serum-free RPMI 1640 . Tumour growth and viability of the embryo were controlled daily by stereo microscopy.

In vivo apoptosis induction Tumours were established as described 3 days after the inoculation of tumours on the CAM, sodium butyrate or tributyrin was administered intravenously (i.v.) into the CAM vessels using a $0.3 \times 13 \mathrm{~mm}$ needle in a total volume of $100 \mu \mathrm{l}$. The final in vivo concentration was calculated for a total blood volume of $2 \mathrm{~cm}^{3}$ and varied from 0.1 to $5.0 \mathrm{~mm}$ for tributyrin and sodium butyrate. At $48 \mathrm{~h}$ after application, the tumour, together with the CAM, was sampled for immunohistochemistry and apoptosis detection.

Quantitative assessment of apoptosis in implanted tumours The detection of apoptotic cells was performed as described previously (Maier et al, 2000). Tumours were sampled 5 days after seeding and embedded in paraffin. Sections of $3 \mu \mathrm{m}$ were mounted on poly-L-lysine-coated slides. After deparaffinising and rehydration, slides were washed twice in PBS and treated with $0.1 \% \mathrm{H}_{2} \mathrm{O}_{2}$ in PBS for $15 \mathrm{~min}$. After repeated washing in $\mathrm{dH}_{2} \mathrm{O}$ and TdT buffer $(30 \mathrm{mM}$ Tris, $\mathrm{pH} 7.2,140 \mathrm{~mm}$ sodium cacodylate, $1 \mathrm{~mm}$ cobalt chloride), slides were incubated with TdT-Biotin-dUTP mix $(100 \mu \mathrm{l}$ TdT buffer, $30 \mathrm{U}$ TdT, $0.5 \mu \mathrm{l}$ Biotin-dUTP; Boehringer Mannheim, Indianapolis, IN, USA) for $1 \mathrm{~h}$ at $37^{\circ} \mathrm{C}$ in a humid chamber. The reaction was stopped and unspecific binding was blocked by incubation in 2\% BSA for $10 \mathrm{~min}$ at room temperature. Slides were incubated with a secondary antibody ( $A B C$ Vectastain, Vector Laboratories, Inc., Burlingame, CA, USA) for $30 \mathrm{~min}$ in a humid chamber at room temperature. Slides were washed and stained with 3-amino-9-ethylcarbazol (AEC). After washing in $\mathrm{dH}_{2} \mathrm{O}$, slides were counterstained with haematoxylin, dehydrated and mounted. For determination of apoptosis, 500 cells were evaluated in representative fields at $\times 400$ magnification, and apoptotic cells were calculated in percent of the total number of counted cells.

\section{Growth of cells in nude mice and procedure of treatment}

Evaluation of drug-induced effects in the mouse model was performed using fast growing, hormone-independent PC3 and TSU-PR1 cells. Cells were maintained in culture as described and found to be free of mycoplasma contamination. Cells were harvested from tissue culture flasks after reaching semiconfluence. Before injection, cells were washed and resuspended in Dulbecco's phosphate-buffered saline (PBS). In all, $10^{5}$ cells were transplanted on both sides subcutaneously through $0.4 \times 19 \mathrm{~mm}$ needles in projection of the scapulae of 7-week-old NMR/-nu/nu male mice with a mean weight of $30 \mathrm{~g}$ (Bomholtgard, Denmark). For each treatment protocol, six mice were used resulting in 12 tumours per setting. For intraperitoneal application, both sodium butyrate and tributyrin were dissolved in sterile saline. Treatment was started $24 \mathrm{~h}$ after implantation of the cells. During the first week, drug administration was performed on a daily basis for a calculated final plasma concentration of $10 \mathrm{~mm}$. As the mice were estimated with a $2.4 \mathrm{ml}$ blood volume, $24 \mathrm{mg}$ of sodium butyrate and $7.9 \mathrm{mg}$ of tributyrin were used (Egorin et al, 1999). From week 2 until the end of week 4, when the experiment was stopped, application was carried out every second day. As control, a mock-treated group with mice growing xenograft tumours and getting normal saline injections was observed. Tumour size was measured once a week and tumour volume was calculated according to the formula 1/ $2 \times L \times W \times H$ in millimetres (Tomayko and Reynolds, 1989). The weight of all mice was measured weekly. All animal experiments were carried out with ethical committee approval (\#631, Regierungspräsidium Tübingen, Germany) and met the standards as defined by the UKCCCR guidelines (Workman et al, 1998).

\section{Immunohistochemistry and quantitative assessment of KI-67 protein expression}

Detection of the nuclear protein Ki-67 has been chosen, as it is preferentially expressed during the active phases of the cell cycle, but not in the G0-phase. Ki-67 is an accepted means for the detection of proliferating cells in paraffin-embedded tissue sections (Cattoretti et al, 1992; Gerdes et al, 1992; Mucci et al, 2000), and its expression has been shown to be associated with poor outcome in prostate cancer patients (Borre et al, 1998). Standard avidin-biotin complex immunohistochemistry was used for staining the animal tumours. Pretreatment was performed by exposure for $10 \mathrm{~min}$ in sodium citrate buffer in a microwave oven. The slides were then incubated sequentially with primary antibody (1:100 dilution, monoclonal mouse anti-human-Ki-67 antibody, DAKO Diagnostika, Hamburg, Germany), biotinylated secondary antibody, avidin - biotin complex and chromogenic substrate $3,3^{\prime}$ diaminobenzidine. Slides were evaluated for adequacy using a standard bright field microscope. Digital images were acquired and protein expression was scored as positive or negative using the 
MDS 5.8 system from Applied Imaging Corporation (Santa Clara, CA, USA). For objective evaluation, eight representative areas were defined. In the case of KI-67 protein expression, the system was optimised for nuclear staining, calculating the percentage of stained nuclei. Data were transferred to a spreadsheet for subsequent analysis.

\section{Western blotting}

The expression of proteins was determined by Western blot analysis using specific primary antibodies for $\mathrm{p} 21 \mathrm{WAF} 1, \mathrm{Rb}$ and cmyc (Oncogene, Cambridge, USA). Briefly, cells were lysed using RIPA solution ( $1 \%$ nonidet P- $40,0.5 \%$ sodium deoxycholate, $0.1 \%$ SDS, $100 \mu \mathrm{g} \mathrm{ml}^{-1}$ phenylmethylsulphonylfluoride, $30 \mu \mathrm{l} \mathrm{ml}^{-1}$ aprotinin, $50 \mu \mathrm{g} \mathrm{ml}^{-1}$ leupeptin, in PBS, $\mathrm{pH}$ 7.4; chemicals were purchased from Sigma, Steinheim, Germany) at $4^{\circ} \mathrm{C}$ for $10 \mathrm{~min}$. Lysates were centrifuged and the protein concentration of the supernatant was determined using the Bradford assay. Laemmli sample buffer at a ratio of $1: 2$ was mixed to the sample. Following electrophoresis, the proteins were transferred onto polyvinylidene difluoride membranes (Bio-Rad, Munich, Germany). Blocking was carried out with freshly prepared TBST plus $10 \%$ nonfat milk (20 mM Tris- $\mathrm{HCl}, \mathrm{pH} 7.6,137 \mathrm{~mm} \mathrm{NaCl}, 0.1 \%$ Tween-20). After washing, the membrane was incubated for $1 \mathrm{~h}$ with primary antibodies diluted in TBST (100-1.500-fold). Appropriate horseradish peroxidase-conjugated secondary antibodies (Amersham, Buckinghamshire, UK) were incubated overnight. For detection, autoradiography using ECL was performed according to the manufacturer's instructions (Amersham, Buckinghamshire, UK).

\section{Statistical analysis}

Treatment effect was statistically evaluated using the mean score result (i.e. percentage of stained nuclei) for each treatment group (i.e., control, sodium butyrate, tributyrin or various concentrations). To test for significant differences the one-way ANOVA test was performed. To determine the differences between all pairs, post hoc analysis using the Scheffé method was applied. Values are presented in a graphical format using error bars with $95 \%$ confidence intervals (CIs). $P$-values $<0.05$ were considered statistically significant.

\section{RESULTS}

\section{Butyrate-induced growth inhibition in vitro}

Increasing concentrations of sodium butyrate and tributyrin were applied onto the cell lines PC3, TSU-Pr1 and LNCaP starting at a final concentration of $0.5 \mathrm{~mm}$ up to $5.0 \mathrm{~mm}$. Cells were exposed for $72 \mathrm{~h}$ before absorbance was measured using the XTT assay. The titration curve for sodium butyrate is given in Figure 1 for the PC3 cells, demonstrating a $50 \%$ growth inhibition at about $2.5 \mathrm{~mm}$ final concentration. TSU-Pr1 cells were slightly less and the LNCaP cell line was slightly more sensitive to the treatment. Sodium butyrate at a dosage of $0.5 \mathrm{~mm}$ induced already a significant growth inhibition in all the three cell lines compared to mock-treated cells. One-way ANOVA analysis revealed a $P$-value of $<0.0001$. Incubation with equimolar concentrations of tributyrin revealed stronger dose-dependent growth-inhibitory effects (data not shown). This is in accordance with our previous study, where further detailed data were presented (Maier et al, 2000).

Quantitative assessment of in vivo induction of apoptosis in prostate cancer microtumours established on the CAM

Tumours implanted on the CAM were examined quantitatively for apoptosis following exposure to increasing concentrations of sodium butyrate or tributyrin $(0.1-5 \mathrm{~mm})$ by a single i.v. injection.

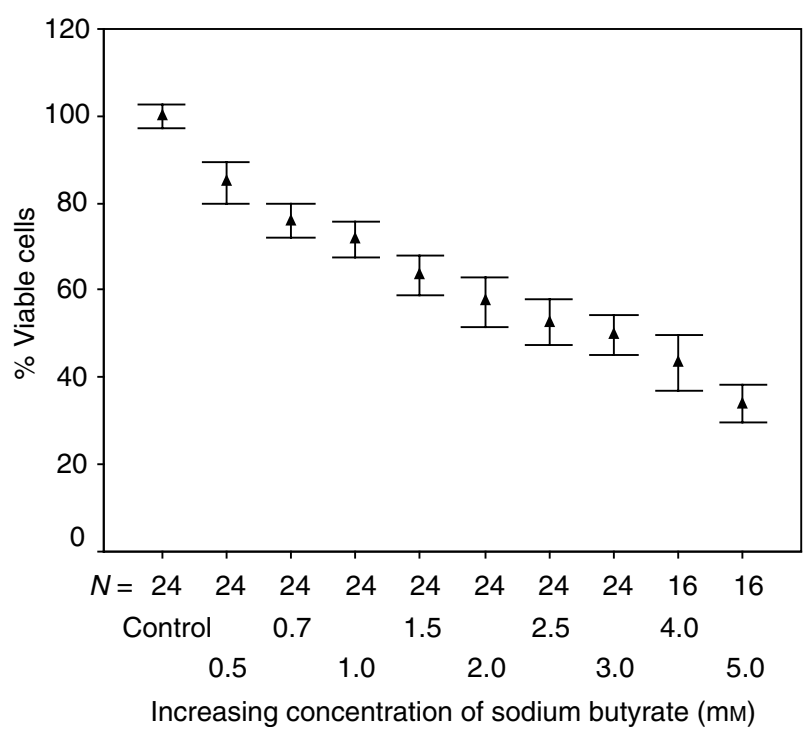

Figure I Increasing concentrations of sodium butyrate were applied on the human prostate cancer cell line PC3 starting at an initial concentration of $0.5 \mathrm{~mm}$ up to $5.0 \mathrm{~mm}$. Growth inhibition was correlated to absorbance determined with the XTT assay. The control was set to 100\%. The percentage of viable cells is given as mean values with standard deviation of repeated experiments.

i.v. Injections of sodium butyrate or tributyrin revealed a strong apoptotic effect in prostate cancer microtumours over mocktreated controls as visible in the tissue sections and demonstrated in Figure $2 \mathrm{~A}-\mathrm{D}$. Both compounds, sodium butyrate and tributyrin, led to a dose-dependent increase of apoptotic cells compared to mock-treated cells. With sodium butyrate, at the maximum concentration of $5.0 \mathrm{~mm}$ the corresponding apoptosis rates were almost similar with $28.7 \pm 5.8,23.0 \pm 2.7$ and $26.0 \pm 5.7 \%$ of apoptotic nuclei in PC3, TSU-PR1 and LNCaP cells, respectively (Figure 3A). When treated with tributyrin (Figure 3B) PC3 cells were the most sensitive and LNCaP cells were less sensitive. After injection of $5.0 \mathrm{~mm}$ tributyrin, the corresponding rate of apoptotic nuclei was $38 \pm 4.5,27.5 \pm 5.3$ and $27.8 \pm 7.5$ for PC3, TSU-PR1 and LNCaP cells, respectively. Compared to a $48 \mathrm{~h}$ sodium butyrate exposure, the percentage of apoptotic cells induced by tributyrin exposure was higher. Interestingly, the dose-response curve of both compounds showed a substantial rate of apoptotic cells compared to mock-treated cells at already very low concentrations of $0.1 \mathrm{~mm}$ of sodium butyrate or tributyrin.

\section{Inhibition of tumour growth in the mouse model}

$\mathrm{NMR} /-\mathrm{nu} / \mathrm{nu}$ male mice (7 weeks old) with an average weight of $30 \mathrm{~g}$ were used for implantation of human prostate cancer cells derived from the cell lines PC3 and TSU-Pr1. These cell lines were chosen for the mouse model as they easily grow without any additional condition media and form homogeneous tumours. As graphically demonstrated in Figure 4A, the volume of the PC3 tumours was increasing over time, with the control group having the largest tumour sizes. After 4 weeks of treatment, the size of the tumours in the control group was almost double the size compared to the treatment groups. Between sodium butyrate and tributyrin treatment, there was no significant difference in tumour size throughout the observation time. With the less fast growing TSUPr1 cells, the tumours in the control and treatment groups were smaller. Still similar in vivo effects for the HDACs were observed applying the identical treatment regimen as for the PC3 cells (Figure 4B). As a parameter to reflect the general condition of the 

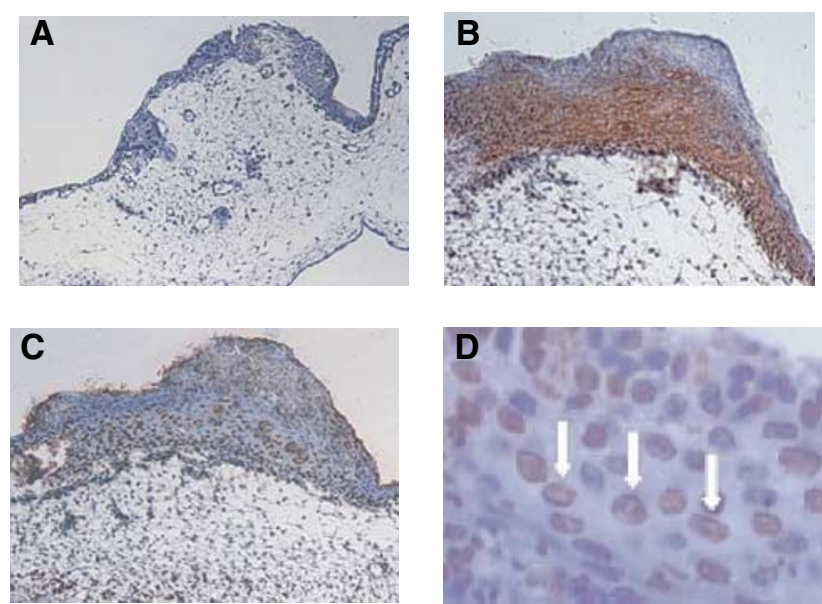

Figure 2 Prostate cancer microtumours growing on the CAM. (A) In the mock-treated control, only very few cells of the tumour, sitting on top of the CAM, show signs of apoptosis. (B) Strong labelling (red staining) of tumour cells by immunohistochemistry with an anti-human antibody to demonstrate the human origin of the evaluated cells (MNF I 6 cytoceratin cocktail (DAKO, Germany). (C) Tributyrin-treated tumours growing on the CAM. TUNEL assay reveals dark brown staining as a correlate to apoptotic changes (magnification $\times 20$ ). (D) Higher magnification of $(\mathbf{C})$. Nuclei-bound staining by TUNEL assay is indicated by white arrows $(\times 800$ magnification)

animals, the weight during the time of the experiments was documented weekly. Substantial loss of weight did not occur in any of the treatment groups during the course of the treatment.

\section{Ki-67 immunohistochemistry of mouse tumours}

Mouse tumours were removed and tissue sections were stained for Ki-67 expression in the nuclei. Control tumours, sodium butyrateand tributyrin-treated tumours had a mean percentage of stained nuclei of 74.9 (standard error (s.e.) $2.0,95 \%$ CI 70.6-79.1), 29.1 (s.e. 3.1, CI 22.8-35.5) and 36.7 (s.e. 2.7, CI 31.2-42.2), respectively. One-way ANOVA analysis revealed a $P$-value of $<0.0001$. To examine specifically the difference between the different treatment types, a post hoc pairwise comparison was performed. Control tumours demonstrated a significantly higher percentage of $\mathrm{Ki}-67$-stained nuclei as compared to sodium butyrate-treated tumours (Scheffé method, $P<0.0001$, CI $36.5-$ 54.9). Sodium butyrate-treated mice showed no significant different percentage of $\mathrm{Ki}$-67-stained nuclei as compared to tributyrin-treated tumours (Scheffé $P=0.14$; CI -16.9 to 1.8 ). The percentage of $\mathrm{Ki}-67$-stained nuclei for the three groups is graphically demonstrated in Figure 5 for PC3-implanted tumours. Examples of immunohistochemistry are also given, with Ki-67 staining the nuclei of dark brown cells that are in an active phase of the cell cycle.

\section{Expression of $\mathrm{p} 21, \mathrm{Rb}$ and $\mathrm{c}-\mathrm{myc}$}

For Western blot analysis, cells were treated with a final concentration of $5.0 \mathrm{~mm}$ sodium butyrate. Protein expression of the specific targets $\mathrm{p} 21, \mathrm{Rb}$ and c-myc, is demonstrated for PC3 cells in Figure 6. Lysates representing different treatment times, that is, 12 and 24 and $48 \mathrm{~h}$ treatment, were run simultaneously on the same gel, loading equal amounts of protein. The cell cycle inhibitor p21 was not expressed in untreated PC3 (and TSU-Pr1) cells, which were both not expressing a wild-type p53. After exposure to sodium butyrate, p21 expression was induced with a maximum at $12 \mathrm{~h}$ post-treatment. $\mathrm{P} 21$ possibly could affect $\mathrm{c}-\mathrm{myc}$ expression via inhibition of cyclin-CDK-dependent phosphoryla-

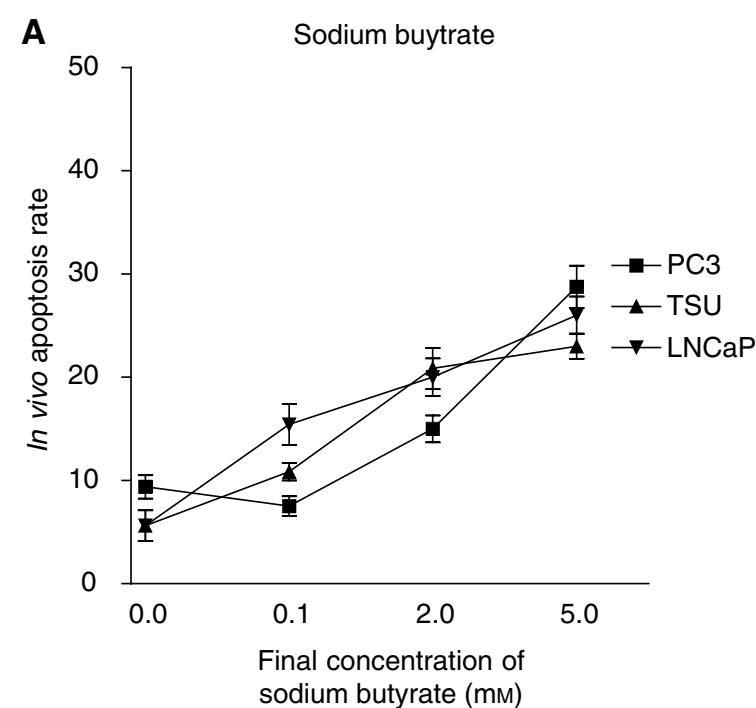

B Tributyrin

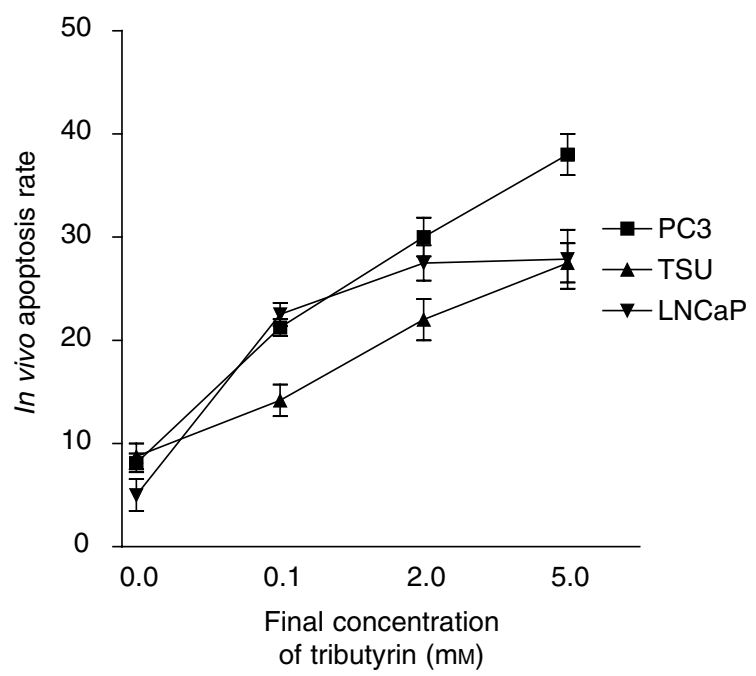

Figure 3 (A) Induction of apoptosis in LNCaP, PC3 and TSU-PrI human prostate cancer cells by increasing concentrations of sodium butyrate. The final in vivo concentration of i.v.-applied sodium butyrate varied from 0.1 to $5.0 \mathrm{~mm}$. Normal saline injection served as a negative control. Apoptotic cells were assessed using the TUNEL assay. (B) Induction of apoptosis in the three cell lines LNCaP, PC3 and TSU-PrI with increasing concentrations of tributyrin.

tion of Rb. Western blot analysis revealed an Rb-dephosphorylation after exposure to sodium butyrate in a time-dependent pattern. Simultaneously, c-myc expression decreased, supporting the hypothesis of a p21 $>\mathrm{Rb}>\mathrm{c}$-myc-dependent pathway underlying the butyrate-induced growth-inhibitory effects.

\section{DISCUSSION}

While effective surgical and radiation treatment options can be offered for clinically localised prostate cancer, advanced prostate cancer remains incurable. Androgen ablation has been the standard treatment for metastatic prostate cancer for many years. Despite an initial response to antiandrogens, disease progresses in the majority of cases independent of hormonal status. Unfortunately, the surviving cell clones are resistant to standard cytotoxic chemotherapies as well. Not surprisingly, early clinical trials have 


\section{A}

PC3
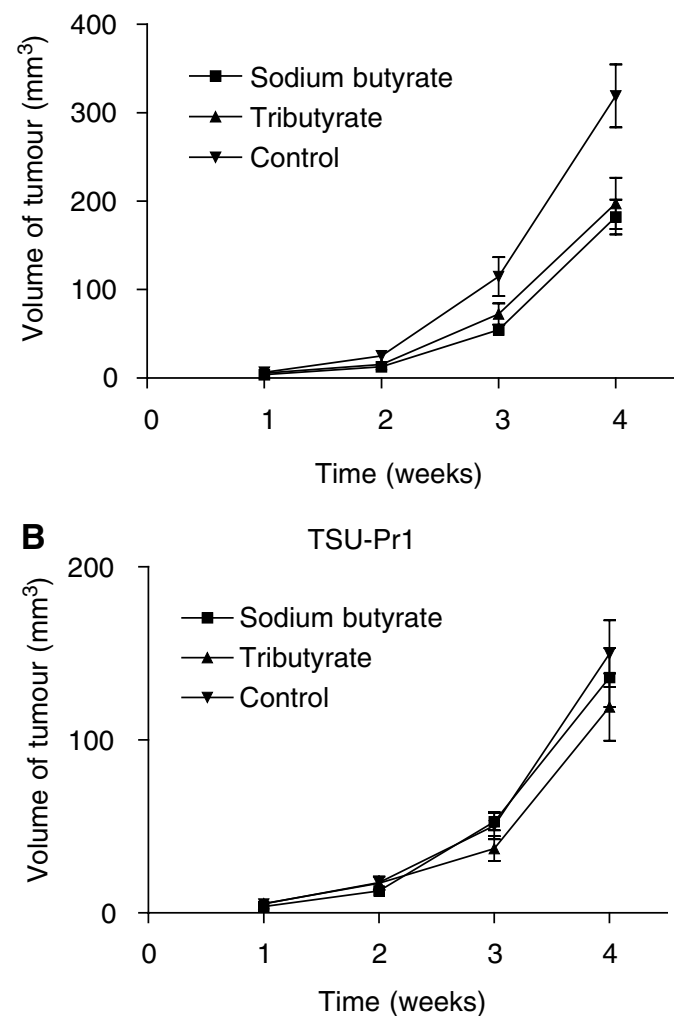

Figure 4 (A) PC3 cells were transplanted in male nude mice. Tumour volume was measured once weekly and is given as an average of 12 tumours. The mice were treated with either normal saline, sodium butyrate or tributyrin by i.p. injections with an estimated plasma concentration of $10 \mathrm{mM}$ for the compounds. (B) Tumour volume after implantation of TSU$\mathrm{Prl}$ prostate cancer cells in male nude mice. Same control and treatment groups as given in (A) for PC-3 cells.

demonstrated only a very limited benefit in patients with advanced prostate cancer disease (Yagoda and Petrylak, 1993). The chemotherapy regimen was partly unsuccessful as patients had large symptomatic tumour burden, and due to their advanced age often presented with confounding comorbidities. The patients with advanced disease nowadays present a lot earlier and due to the merit of up-to-date medicine mostly with well-controlled comorbidities. These clinical aspects and increasing knowledge about biomolecular conditions of prostate cancer based on new technologies (Dhanasekaran et al, 2001) facilitate the identification of new chemopreventive and chemotherapeutic options for the treatment of prostate cancer. Novel agents often influence pathways that are underlying prostate cancer growth and survival. The rationale for this type of approach is the hope of increased antitumour activity with less toxicity, as those pathways are targeted that are critical for malignant but not for normal cell differentiation, proliferation and survival. One of the promising groups of drugs is the HDACs.

In our previous study, we have shown several in vitro effects caused by treatment of PC3, TSU-Pr1 and LNCaP cells with sodium butyrate or tributyrin (Maier et al, 2000). These effects included cell swelling, nuclear disruption, cell cycle arrest in the G1 phase and dose-dependent induction of apoptosis. In the XTT assay analysis in this study, the LNCaP cell line was most sensitive compared to PC3 and TSU-Pr1 cells. This could possibly be explained by the fact that LNCaP cells are known to be a cell line expressing prostatic markers and being hormone sensitive, whereas PC3 and TSU-Pr1 cells are less differentiated (Kaighn
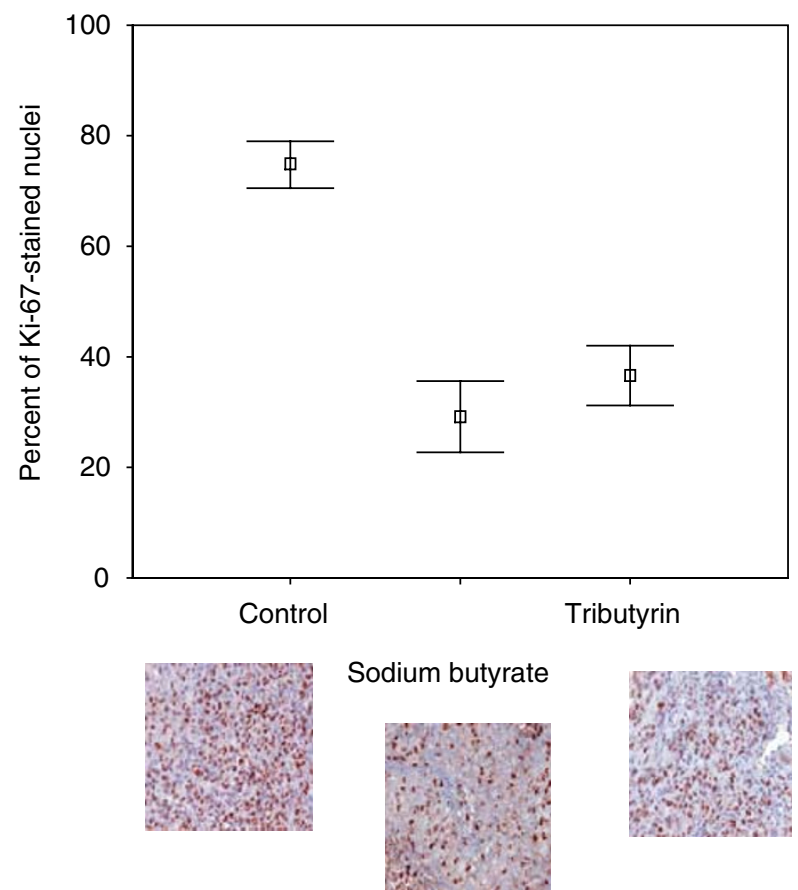

Figure 5 Immunohistochemistry was performed for protein expression of Ki-67. Control mouse tumours, sodium butyrate- and tributyrin-treated mouse tumours were stained with anti-human Ki-67 monoclonal antibody. Ki-67-positive cells are stained dark brown. Nuclear staining was evaluated with a computerised system. Mean percentages of positive nuclei are graphically given with $95 \% \mathrm{Cl}$. Examples of tissue sections stained for Ki-67 for the control group, the sodium butyrate- and tributyrin-treated group are given.

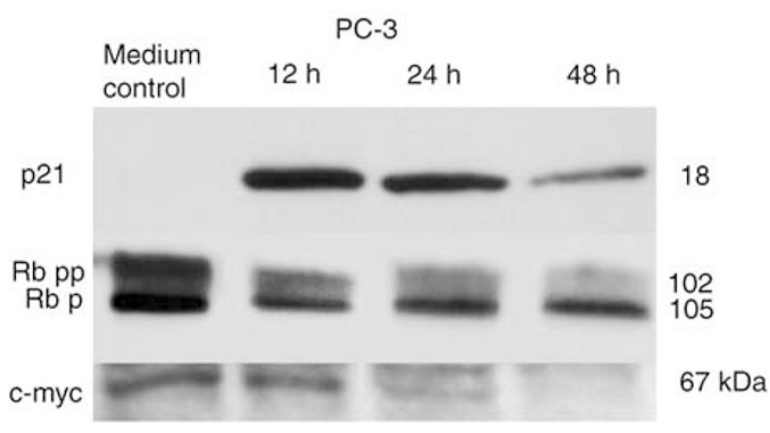

Figure 6 Western blot analysis using specific antibodies for detection of p2 I, Rb and c-myc expression. The presented blots represent expression of the targets of sodium butyrate-treated PC3 human prostate cancer cells. Expression was evaluated at several time points after treatment (internal loading control not shown). P2I expression was induced by sodium butyrate with a maximum at $12 \mathrm{~h}$ post-treatment. $\mathrm{Rb}$ expression shifted to the hypophosphorylated form in a time-dependent pattern. Simultaneously, c-myc expression decreased. Molecular weights are given in kDa.

et al, 1979; Horoszewicz et al, 1983; Webber et al, 1996). PC3 and TSU-Pr1 cells carry molecular alterations such as a mutated p53 and the origin of TSU-Pr1 cells is discussed controversially (Iizumi et al, 1987; van-Bokhoven et al, 2001). On the chicken egg membrane, PC3 tumours seemed to be more sensitive especially when treated with tributyrin. For all cell lines it could be noted, in accordance with the reported in vitro observations, that sensitivity was higher when treated with tributyrin. The parameter chosen for quantification of the treatment effect was the number of apoptotic cells. This experiment demonstrates that the used butyrates show 
in vivo efficiency via the induction of apoptosis. The verification of cells of human origin was carried out by immunohistochemistry using a cytokeratin antibody cocktail. Based on the promising results of this in vivo model, mouse experiments were conducted for verification. In the mouse experiments we aimed for a plasma concentration of $10 \mathrm{~mm}$ for both drugs according to published pharmacological calculations for butyrates (Egorin et al, 1999). Although it could be demonstrated that relevant plasma concentrations can be achieved by oral administration (Egorin et al, 1999) in this study, drug application was performed by injection. Drug application by mixing the substances with the food did not prove to be effective as the pellets were partly disregarded by the animals, resulting in considerable variations of plasma levels. In comparison to the very sensitive CAM assay, in which a similar treatment effect as observed in the cell culture experiments was achieved with a single dose, a much higher total dosage was needed in the mouse model. This is most likely due to delivery and metabolism (Miller et al, 1987). During the course of 4 weeks, more resistant cell clones most probably do not emerge. The tumour size was significantly less increasing in the treated animals with no significant difference between sodium butyrate or tributyrin applied with equal final plasma concentration. None of the mice died due to acute toxic treatment effects and none of the animals showed major changes in the weight as a parameter for good drug tolerance. The tumour sizes correlate well with the percentage of Ki-67-stained nuclei as observed by immunohistochemistry and computerised objective evaluation. In this study, the Ki-67-positive cells were significantly less in the treated group compared to the control group of untreated mice. Increased differentiation induced by butyrates has been shown earlier in in vitro experiments using the LNCaP cell lines (Carducci et al, 1996).

The given immunoblot results suggest that the mechanism for a treatment effect by butyrates is independent of a wild-type p-53 status (Carducci et al, 1996). Overexpression of p21 has been shown to activate $\mathrm{Rb}$ (Agarwal et al, 1998; Keegan et al, 1998). Rb is known to be functionally active in an underphosphorylated conformation and is inactivated during the late G1 phase by cyclindependent phosphorylation, allowing the cells to proceed from G1 to $S$ phase (Zhao et al, 1997). The given results suggest that an intact $\mathrm{p} 21, \mathrm{Rb}$ and $\mathrm{c}$-myc may have to be present for treatment effect. A similar observation has been made for a novel HDAC inhibitor FK228 (Sasakawa et al, 2003). Still, the given data obviously look only at a very small portion of possibly involved pathways and thus have to be considered as preliminary. It cannot be ruled out that the observed changes could be a parallel issue as for example growth inhibition, induced by sodium butyrate, has been described in a cell line that has abrogated $\mathrm{Rb}$ function (Rashid et al, 2001). There might be other and potentially even more important structures such as cyclin A and D, p27 and protein kinase $C$, which are involved in the process of butyrate-induced growth inhibition (Chen et al, 2003; Kim et al, 2003; Siddiqui et al, 2003). Nevertheless, exploring the activation of p-21, including the role of $\mathrm{Sp} 1$ transcription factor, is a very promising approach
(Wang et al, 2000; Rashid et al, 2001; Margueron et al, 2003), as this gene appears to be rarely mutated in common human malignancies in contrast to p53 (Terao et al, 2001). A similar pattern of mechanism has been described for several cell lines including prostate cancer cell lines for the effect of phorbol ester (Blagosklonny et al, 1997). This observation possibly suggests that a combination of phorbol ester and butyrates may have an additive effect on tumour cells (McBain et al, 1996; Rahmani et al, 2002).

In contrast to the majority of solid tumours, prostate cancer is a very heterogeneous tumour, which is obvious for example in the various Gleason patterns represented in one gland (Gleason, 1966). New technologies such as laser microdissection help to gain an insight into the underlying patho-morphologies of distinct tumour cells (Rubin, 2002). This may aid in understanding the complexity of intervening pathways of prostate cancer growth. From this understanding, it is likely that monotherapy might not be sufficient for treatment but rather a combination of drugs targeting various mechanisms. Based on the presented in vivo results, butyrates are very promising agents in prostate cancer control independent of hormone sensitivity. The anticancer effects might be supported by a combination with other drugs and a combined treatment approach may offer the chance to a reduced dosage with less side effects (Newmark and Young, 1995; Conley et al, 1998; Halicka et al, 2000; Banwell et al, 2003).

In this study, we have demonstrated a substantial in vivo treatment effect, which can be induced by the application of sodium butyrate or the orally applicable tributyrin in human prostate cancer. These two HDACs have shown a strong cell growth-inhibitory and proapoptotic activity. These effects seem to be independent of p53 status and a pathway including p21, Rb and $\mathrm{c}$-myc is possibly involved in these effects. The given in vivo results may provide the rationale to apply these HDACs in well-controlled clinical trials as 'gene-regulating chemoprevention' in patients being at high risk of recurrence after specific therapy or as 'generegulating chemotherapy' in a combination regimen for patients with locally or distant advanced prostate cancer.

\section{ACKNOWLEDGEMENTS}

All authors of the article have declared that there are no commercial affiliations, stock interests or patent licenses of potential conflict of interest with the presented work. There are no financial interests of a company whose product has been used for studies in the work presented in the paper. This work was supported by the Medical Faculty, University of Ulm, Germany and by the Deutsche Forschungsgemeinschaft (Gs 8/5-1), Bonn, Germany. Our special thanks go to Michaela Eggel for excellent support in culturing and maintaining cells for all experiments, and to Mark A Rubin, Chief Urologic Pathology, Harvard Medical School for providing expert support with immunohistochemistry.

\section{REFERENCES}

Agarwal ML, Taylor WR, Chernov MV, Chernova OB, Stark GR (1998) J Biol Chem 273: 1-4

Banwell CM, Singh R, Stewart PM, Uskokovic MR, Campbell MJ (2003) Recent Results Cancer Res 164: 83-98

Blagosklonny MV, Prabhu NS, El-Deiry WS (1997) Cancer Res 57: 320-325

Borre M, Bentzen SM, Nerstrom B, Overgaard J (1998) J Urol 159: $1609-1614$

Carducci MA, Nelson JB, Chan-Tack KM, Ayyagari SR, Sweatt WH, Campbell PA, Nelson WG, Simons JW (1996) Clin Cancer Res 2: 379-387

Cattoretti G, Becker MH, Key G, Duchrow M, Schluter C, Galle J, Gerdes J (1992) J Pathol 168: 357-363

Chen JS, Faller DV, Spanjaard RA (2003) Curr Cancer Drug Targets 3: 219-236

Chen ZX, Breitman TR (1994) Cancer Res 54: 3494-3499

Claassen GF, Hann SR (2000) Proc Natl Acad Sci USA 97: 9498-9503

Conley BA, Egorin MJ, Tait N, Rosen DM, Sausville EA, Dover G, Fram RJ, Van-Echo DA (1998) Clin Cancer Res 4: 629-634

Dhanasekaran SM, Barrette TR, Ghosh D, Shah R, Varambally S, Kurachi K, Pienta KJ, Rubin MA, Chinnaiyan AM (2001) Nature 412: $822-826$

Egorin MJ, Yuan ZM, Sentz DL, Plaisance K, Eiseman JL (1999) Cancer Chemother Pharmacol 43: 445-453 
Gerdes J, Becker MH, Key G, Cattoretti G (1992) J Pathol 168: 85 -86

Gleason DF (1966) Cancer Chemother Rep 50: 125-128

Gleave ME, Sato N, Sadar M, Yago V, Bruchovsky N, Sullivan L (1998) J Cell Biochem 69: $271-281$

Halicka HD, Murakami T, Papageorgio CN, Mittelman A, Mikulski SM, Shogen K, Darzynkiewicz Z (2000) Cell Prolif 33: $407-417$

Heerdt BG, Houston MA, Anthony GM, Augenlicht LH (1999) Cancer Res 59: $1584-1591$

Horoszewicz JS, Leong SS, Kawinski E, Karr JP, Rosenthal H, Chu TM, Mirand EA, Murphy GP (1983) Cancer Res 43: 1809-1818

Iizumi T, Yazaki T, Kanoh S, Kondo I, Koiso K (1987) J Urol 137: $1304-1306$

Jemal A, Thomas A, Murray T, Thun M (2002) CA Cancer J Clin 52: 23-47

Kaighn ME, Narayan KS, Ohnuki Y, Lechner JF, Jones LW (1979) Invest Urol 17: 16-23

Keegan PE, Lunec J, Neal DE (1998) Br J Urol 82: 710-720

Kim YK, Han JW, Woo YN, Chun JK, Yoo JY, Cho EJ, Hong S, Lee HY, Lee YW, Lee HW (2003) Oncogene 22: 6023-6031

Kunzi-Rapp K, Genze F, Kufer R, Reich E, Hautmann RE, Gschwend JE (2001) J Urol 166: 1502-1507

Maier S, Reich E, Martin R, Bachem M, Altug V, Hautmann RE, Gschwend JE (2000) Int J Cancer 88: 245-251

Margueron R, Licznar A, Lazennec G, Vignon F, Cavailles V (2003) J Endocrinol 179: $41-53$

McBain JA, Eastman A, Simmons DL, Pettit GR, Mueller GC (1996) Int I Cancer 67: 715-723

Miller AA, Kurschel E, Osieka R, Schmidt CG (1987) Eur J Cancer Clin Oncol 23: $1283-1287$

Mucci NR, Rubin MA, Strawderman MS, Montie JE, Smith DC, Pienta KJ (2000) J Natl Cancer Inst 92: 1941 - 1942

Newmark HL, Young CW (1995) J Cell Biochem 22(Suppl): $247-253$

Picus J, Schultz M (1999) Semin Oncol 26: 14-18
Planchon P, Pouillart P, Ronco G, Villa P, Pieri F (1993) J Pharm Sci 82: $1046-1048$

Rahmani M, Dai Y, Grant S (2002) Exp Cell Res 277: $31-47$

Rashid SF, Moore JS, Walker E, Driver PM, Engel J, Edwards CE, Brown G, Uskokovic MR, Campbell MJ (2001) Oncogene 20: $1860-1872$

Roehm NW, Rodgers GH, Hatfield SM, Glasebrook AL (1991) J Immunol Methods 142: 257-265

Rubin MA (2002) Science 296: $1329-1330$

Samson DJ, Seidenfeld J, Schmitt B, Hasselblad V, Albertsen PC, Bennett CL, Wilt TJ, Aronson N (2002) Cancer 95: $361-376$

Sasakawa Y, Naoe Y, Inoue T, Sasakawa T, Matsuo M, Manda T, Mutoh S (2003) Cancer Lett 195: $161-168$

Schroder C, Eckert K, Maurer HR (1998) Int J Oncol 13: 1335-1340

Siddiqui H, Solomon DA, Gunawardena RW, Wang Y, Knudsen ES (2003) Mol Cell Biol 23: 7719-7731

Terao Y, Nishida J, Horiuchi S, Rong F, Ueoka Y, Matsuda T, Kato H, Furugen Y, Yoshida K, Kato K, Wake N (2001) Int J Cancer 94: $257-267$

Tomayko MM, Reynolds CP (1989) Cancer Chemother Pharmacol 24: $148-154$

van-Bokhoven A, Varella-Garcia M, Korch C, Miller GJ (2001) Cancer Res 61: $6340-6344$

Wang CH, Tsao YP, Chen HJ, Chen HL, Wang HW, Chen SL (2000) Biochem Biophys Res Commun 270: 303-310

Webber MM, Bello D, Quader S (1996) Prostate 29: 386-394

Workman P, Twentyman P, Balkwill F, Balmain A, Chaplin D, Double J, Embleton J, Newell D, Raymond R, S J, Stephens T, Wallace J (1998) Br J Cancer 77: $1-10$

Yagoda A, Petrylak D (1993) Cancer 71: 1098 - 1109

Zhao X, Gschwend JE, Powell CT, Foster RG, Day KC, Day ML (1997) J Biol Chem 272: $22751-22757$ 